\title{
Screening for symptoms of anxiety and depression in patients admitted to a university hospital with acute coronary syndrome
}

\author{
Rastreio de sintomas ansiosos e depressivos em pacientes com síndrome \\ coronariana aguda internados em um hospital universitário
}

Carolina Casanova Meneghetti, Bruno Luiz Guidolin, Paulo Roberto Zimmermann, Ana Sfoggia*

\begin{abstract}
Objective: To investigate the prevalence of anxiety and depression in patients admitted for acute coronary syndrome to a university hospital and to examine associations with use of psychotropic drugs.

Methods: Ninety-one patients who had had an acute coronary event were enrolled on this cross-sectional prevalence study. Characteristics of the study population and the prevalence rates of depression and anxiety in the sample were assessed using the Hospital São Lucas da Pontifícia Universidade Católica do Rio Grande do Sul (PUCRS) psychiatric consultation protocol, which includes clinical and sociodemographic data, and the Hospital Anxiety and Depression Scale (HADS).

Results: The prevalence of symptoms of anxiety was $48.4 \%$ (44 patients) and the prevalence of depressive symptoms was $26.4 \%$ ( 24 patients). Of these, 19 patients $(20.9 \%$ of the whole sample) had scores indicative of both types of symptoms concomitantly. Considering the whole sample, just 17 patients $(18.7 \%)$ were receiving treatment for anxiety or depression with benzodiazepines and/or antidepressants.

Conclusions: Anxiety and depression are disorders that are more prevalent among patients with acute coronary syndrome than in the general population, but they are generally under-diagnosed and under-treated. Patients with anxiety and depression simultaneously had higher scores on the HADS for anxiety and depression and therefore require more intensive care.
\end{abstract}

Keywords: Anxiety, depression, HADS, acute coronary syndrome, psychopharmaceuticals.

\section{Resumo}

Objetivo: Investigar a prevalência de ansiedade e depressão em pacientes com síndrome coronariana aguda internados em um hospital universitário e examinar sua associação com o uso de drogas psicotrópicas.

Métodos: Noventa e um pacientes que sofreram evento coronariano agudo foram incluídos nesse estudo transversal de prevalência. O protocolo de interconsulta psiquiátrica do Hospital São Lucas da Pontifícia Universidade Católica do Rio Grande do Sul (PUCRS), com os dados clínicos e sociodemográficos, e a Escala Hospitalar de Ansiedade e Depressão (HADS) foram utilizados para avaliar as características da população estudada e a prevalência de depressão e ansiedade nessa amostra.

Resultados: A prevalência de sintomas ansiosos foi de $48,4 \%$ (44 pacientes), e a de sintomas depressivos, de 26,4\% (24 pacientes). Desses, 19 (20,9\% do total da amostra) pontuaram para os dois sintomas concomitantemente. Considerando a amostra como um todo, apenas 17 pacientes $(18,7 \%)$ estavam recebendo tratamento para ansiedade ou depressão com benzodiazepínicos e/ou antidepressivos.

Conclusão: Ansiedade e depressão são transtornos mais prevalentes em pacientes com síndrome coronariana aguda do que na população geral, mas geralmente são subdiagnosticados e subtratados. Os pacientes com presença simultânea de ansiedade e depressão apresentam escores mais altos na escala HADS para ansiedade e depressão e necessitam, portanto, de um controle mais intensivo.

Descritores: Ansiedade, depressão, HADS, síndrome coronariana aguda, psicofármacos.

* Pontifícia Universidade Católica do Rio Grande do Sul (PUCRS), Porto Alegre, RS, Brazil.

Financial support: none.

Submitted Jan 06 2016, accepted for publication Oct 01 2016. No conflicts of interest declared concerning the publication of this article.

Suggested citation: Meneghetti CC, Guidolin BL, Zimmermann PR, Sfoggia A. Screening for symptoms of anxiety and depression in patients admitted to a university hospital with acute coronary syndrome. Trends Psychiatry Psychother. 2017;39(1):12-18. http://dx.doi.org/10.1590/2237-6089-2016-0004 


\section{Introduction}

According to the World Health Organization, ${ }^{1}$ cardiovascular diseases, including coronary artery disease (CAD), are still the number one cause of death globally, despite all of the efforts made to prevent and treat their risk factors.

Psychological factors, such as anxiety and depression are often found in patients with CAD and they have a significant impact on their treatment and prognosis. ${ }^{2-4}$ In 2008, the American Heart Association ( $\mathrm{AHA}$ ) recommended routine screening for depression in patients with $\mathrm{CAD},{ }^{5}$ and in 2014 they raised depression to the status of a risk factor for acute coronary syndrome (ACS). ${ }^{6}$ Screening for anxiety was not included in the AHA recommendation, even though there is ample evidence that anxiety also has a negative impact on prognosis in $C A D$ and that this impact is independent of depression. ${ }^{7}$ However, its role as a risk factor is less clear when compared to that of depression. ${ }^{8}$

Depression has been identified as the most common diagnosis among people hospitalized for physical diseases. Around $15-20 \%{ }^{9-13}$ of cardiac inpatients meet the diagnostic criteria for major depressive disorder, while around $25-65 \%$ report at least one depressive symptom, ${ }^{9,14}$ which contrasts with the prevalence of approximately $10 \%$ in the general population over the course of a lifetime. ${ }^{14}$ Despite the prognostic importance of depression in cardiac patients, studies indicate that depressive disorders are diagnosed in less than $15 \%$ of cases. ${ }^{14,15}$

Anxiety disorders affect up to $20 \%$ of patients at different stages of $C A D^{9,16-19}$ and in patients with acute myocardial infarction (AMI) the in-hospital anxiety rate is 30 to $40 \% .^{20-22}$ Anxiety amplifies the negative effects of depression on the quality of life of patients with $C A D$ and also increases their need for healthcare after the acute coronary event. ${ }^{22}$

Although depression and anxiety are recognized as independent risk factors for development of CAD, ${ }^{23,24}$ few studies have been conducted in Brazil with the objective of identifying the prevalence of these psychiatric pathologies in patients with CAD.

The objective of this study is to determine the prevalence of symptoms of anxiety and depression among patients admitted with acute coronary syndrome (AMI or unstable angina) by the cardiology team to the Hospital São Lucas (HSL), run by the Pontifícia Universidade Católica do Rio Grande do Sul (PUCRS). A secondary objective was to examine associations between these symptoms and use of psychopharmaceuticals by the patients.

\section{Methods}

\section{Sample}

This is a cross-sectional study with prospective collection of data on 91 patients admitted to hospital from May to October 2015 with acute coronary syndrome (AMI or unstable angina). These patients were admitted by the cardiology team at the PUCRS HSL, were considered stable by the treating team, and were assessed at least 48 hours after hospital admissions by a medical assessor who was a psychiatry resident.

Patients were excluded if they had a diagnosis of moderate or severe mental retardation (ICD F71 or F72 disorders ), exhibited cognitive difficulties at the time the instruments were administered, were less than 18 years old (on the date that they were asked to sign a free and informed consent form), or refused to participate in the study.

A total of 92 patients were sampled by convenience and interviewed. One of these 92 patients was excluded from the analysis because of cognitive difficulties at the time the instrument was administered.

\section{Ethical considerations}

All patients enrolled agreed to take part in the study and signed a free and informed consent form.

The study was approved by the scientific commission at the PUCRS HSL and by the PUCRS Research Ethics Committee, under protocol number 1.323.524.

\section{Instruments}

Patients answered questions from the PUCRS HSL psychiatric consultation protocol, which covers clinical and sociodemographic data and were screened for symptoms of anxiety and depression using the Hospital Anxiety and Depression Scale (HADS). Clinical data and length of hospital stay were acquired by review of medical records.

The psychiatric consultation protocol covers basic patient identification data: sex, age, color, income, educational level, religion, marital status and employment status and clinical data on smoking, current alcohol and illicit substance usage, presence of clinical comorbidities (hypertension, diabetes mellitus, and dyslipidemia), and psychiatric treatments and psychotropics administered.

The HADS was developed by Zigmond \& Snaith ${ }^{25}$ in 1983 and is used to identify symptoms of anxiety and depression in patients with serious physical health 
problems who have been admitted to hospital for nonpsychiatric reasons. It is a self-administered scale following the Likert model, with scores that range from 0 to 3 for 14 multiple-choice items, seven of which are related to anxiety (HAD-A) and seven of which are related to depression (HAD-D). In contrast with other similar scales, the HADS does not cover somatic symptoms (such as sleep disorders and loss of appetite), which might not be exclusively related to depression since they can be linked to physical disease as well. The HADS has been used to help diagnose anxiety and depression in patients with cardiac diseases, including coronary disease. ${ }^{14,26-30}$

The authors suggest that scores greater than or equal to 8 indicate presence of a disorder (anxiety and/or depression). ${ }^{25}$ Validation of the Portuguese version demonstrated sensitivity of $93.7 \%$ for HAD-A, sensitivity of $84.6 \%$ for HAD-D, specificity of $72.6 \%$ for HAD-A, and specificity of $90.3 \%$ for HAD-D. ${ }^{31}$

\section{Statistical analysis}

Categorical variables were expressed as frequencies and percentages and quantitative variables as means and standard deviations when distributions were symmetrical and as medians and interquartile ranges (percentiles 25 and 75) when asymmetrical. Associations between categorical variables were assessed using the chi-square test or Fisher's exact test. Quantitative variables with symmetrical distribution were compared using Student's t test and those with asymmetrical distribution using the MannWhitney test. Multiple comparisons of the last of these categories were achieved by conducting rank ordering and then comparison with the Tukey post-hoc test. The significance level was set at $5 \%$.

\section{Results}

A total of 91 patients answered the questions on the psychiatric consultation protocol and the HADS scale. Of these, $59(64.8 \%)$ were men. The mean age of the sample was 64 years, varying from 44 to 90 years (standard deviation $[S D]=9.2$ years). The characteristics of the sample are summarized in Table 1. None of the patients reported alcohol or illicit substance abuse.

Table 1 - Table of sociodemographic and clinical characteristics of the sample and HADS scores for patients admitted with acute coronary syndrome to a university hospital from May to October 2015 ( $n=91$ patients)

\begin{tabular}{|c|c|c|c|c|c|}
\hline Characteristics & $\begin{array}{c}n \text { (frequency) } \\
n=91\end{array}$ & $\begin{array}{c}\text { Without } \\
\text { symptoms } \\
\text { of anxiety or } \\
\text { depression } \\
n=42\end{array}$ & $\begin{array}{c}\text { Only symptoms } \\
\text { of anxiety } \\
\text { (HAD-A) } \\
n=25 \\
\end{array}$ & $\begin{array}{c}\text { Only symptoms } \\
\text { of depression } \\
\text { (HAD-D) } \\
n=5\end{array}$ & $\begin{array}{c}\text { Symptoms of } \\
\text { anxiety and } \\
\text { depression } \\
\text { (HAD-A + } \\
\text { HAD-D) } \\
n=19\end{array}$ \\
\hline \multicolumn{6}{|l|}{ Sex } \\
\hline Women & $32(35.2)$ & $13(31.0)$ & $7(28.0)$ & $1(20.0)$ & $11(57.9)$ \\
\hline Men & $59(64.8)$ & $29(69.0)$ & $18(72.0)$ & $4(80.0)$ & $8(42.1)$ \\
\hline \multicolumn{6}{|l|}{ Age } \\
\hline Mean age \pm standard deviation & $64.0 \pm 9.2$ & $64.3 \pm 9.4$ & $63.8 \pm 9.0$ & $65.2 \pm 5.4$ & $63.5 \pm 10.1$ \\
\hline \multicolumn{6}{|l|}{ Educational level } \\
\hline $1-4$ years in education & $30(33.0)$ & $13(31.0)$ & $8(32.0)$ & $2(40.0)$ & $7(36.8)$ \\
\hline 4-8 years in education & $33(36.3)$ & $13(31.0)$ & $9(36.0)$ & $1(20.0)$ & $10(52.6)$ \\
\hline $8-12$ years in education & $18(19.8)$ & $12(28.6)$ & $4(16.0)$ & $1(20.0)$ & $1(5.3)$ \\
\hline $12-16$ years in education & $6(6.6)$ & $2(4.8)$ & $2(8.0)$ & $1(20.0)$ & $1(5.3)$ \\
\hline More than 16 years in education & $4(4.4)$ & $2(4.8)$ & $2(8.0)$ & 0 & 0 \\
\hline \multicolumn{6}{|l|}{ Religion } \\
\hline Atheist/Agnostic & $3(3.3)$ & 0 & $2(8.0)$ & 0 & $1(5.3)$ \\
\hline Catholic & $61(67.0)$ & $27(64.3)$ & $13(52.0)$ & $5(100.0)$ & $16(84.2)$ \\
\hline Evangelical Christian & $10(11.0)$ & $7(16.7)$ & $3(12.0)$ & 0 & 0 \\
\hline Spiritualist & $7(7.7)$ & $3(7.1)$ & $4(16.0)$ & 0 & 0 \\
\hline Others & $10(11.0)$ & $5(11.9)$ & $3(12.0)$ & 0 & $2(10.5)$ \\
\hline \multicolumn{6}{|l|}{ Marital status } \\
\hline Married or living with partner & $53(58.2)$ & $26(61.9)$ & $19(76.0)$ & $2(40.0)$ & $6(31.6)$ \\
\hline Single or separated & $23(25.3)$ & $10(23.8)$ & $3(12.0)$ & $2(40.0)$ & $8(42.1)$ \\
\hline Widowed & $15(16.5)$ & $6(14.3)$ & $3(12.0)$ & $1(20.0)$ & $5(26.3)$ \\
\hline
\end{tabular}




\begin{tabular}{|c|c|c|c|c|c|}
\hline $\begin{array}{l}\text { Income, multiples of minimum } \\
\text { monthly wage* (median, } \\
\text { percentiles } 25 \text { and } 75 \text { ) }\end{array}$ & $1.5(1.0-2.5)$ & $1.5(1.0-2.6)$ & $1.5(1.0-2.8)$ & $1.0(1.0-3.3)$ & $1.0(1.0-2.0)$ \\
\hline \multicolumn{6}{|l|}{ Employment status } \\
\hline Working & $34(37.4)$ & $20(47.6)$ & $8(32.0)$ & $1(20.0)$ & $5(26.3)$ \\
\hline Unemployed & $4(4.4)$ & 0 & $1(4.0)$ & 0 & $3(15.8)$ \\
\hline Retired because of age & $37(40.7)$ & $15(35.7)$ & $11(44.0)$ & $2(40.0)$ & $9(47.4)$ \\
\hline $\begin{array}{l}\text { Retired because of mental } \\
\text { disease }\end{array}$ & 0 & 0 & 0 & 0 & 0 \\
\hline $\begin{array}{l}\text { Retired because of physical } \\
\text { disease }\end{array}$ & $11(12.1)$ & $4(9.5)$ & $4(16.0)$ & $2(40.0)$ & $1(5.3)$ \\
\hline $\begin{array}{l}\text { On benefits because of mental } \\
\text { disease }\end{array}$ & $2(2.2)$ & $1(2.4)$ & $1(4.0)$ & 0 & 0 \\
\hline $\begin{array}{l}\text { On benefits because physical } \\
\text { disease }\end{array}$ & $3(3.3)$ & $2(4.8)$ & 0 & 0 & $1(5.3)$ \\
\hline \multicolumn{6}{|l|}{ Reason for admission } \\
\hline Acute myocardial infarction & $61(67.0)$ & $30(71.4)$ & $12(48.0)$ & $4(80.0)$ & $15(78.9)$ \\
\hline Unstable angina & $30(33.0)$ & $12(28.6)$ & $13(52.0)$ & $1(20.0)$ & $4(21.1)$ \\
\hline \multicolumn{6}{|l|}{ Smoker } \\
\hline Yes & $31(34.1)$ & $13(31.0)$ & $6(24.0)$ & $2(40.0)$ & $10(52.6)$ \\
\hline No & $26(28.6)$ & $13(31.0)$ & $7(28.0)$ & $1(20.0)$ & $5(26.3)$ \\
\hline Ex-smoker & $34(37.4)$ & $16(38.1)$ & $12(48.0)$ & $2(40.0)$ & $4(21.1)$ \\
\hline Arterial hypertension & $74(81.3)$ & $31(73.8)$ & $22(88.0)$ & $4(80.0)$ & $17(89.5)$ \\
\hline Diabetes mellitus & $31(34.1)$ & $16(38.1)$ & $2(8.0)+$ & $2(40.0)$ & $11(57.9)$ \\
\hline Dyslipidemia & $47(51.6)$ & $22(52.4)$ & $14(56.0)$ & $3(60.0)$ & $8(42.1)$ \\
\hline \multicolumn{6}{|l|}{ Psychiatric treatment } \\
\hline With psychiatrist & $9(9.9)$ & $4(9.5)$ & $4(16.0)$ & 0 & $1(5.3)$ \\
\hline None & $61(67.0)$ & $32(76.2)$ & $15(60.0)$ & $3(60.0)$ & $11(57.9)$ \\
\hline In the past & $13(14.3)$ & $6(14.3)$ & $2(8.0)$ & $1(20.0)$ & $4(21.1)$ \\
\hline With a clinician & $8(8.8)$ & $0+$ & $4(16.0) \dagger$ & $1(20.0) \dagger$ & $3(15.8)+$ \\
\hline \multicolumn{6}{|l|}{ Use of psychotropic medications } \\
\hline None & $74(81.3)$ & $38(90.5)+$ & $17(68.0) \dagger$ & $4(80.0)$ & $15(78.9)$ \\
\hline Benzodiazepines & $5(5.5)$ & 0 & $2(8.0)$ & 0 & $3(15.8) \dagger$ \\
\hline Antidepressants & $8(8.8)$ & $4(9.5)$ & $4(16.0)$ & 0 & 0 \\
\hline $\begin{array}{l}\text { Benzodiazepines + } \\
\text { antidepressants }\end{array}$ & $4(4.4)$ & 0 & $2(8.0)$ & $1(20.0) \dagger$ & $1(5.3)$ \\
\hline \multicolumn{6}{|l|}{$\begin{array}{l}\text { Prescription medications while in } \\
\text { hospital }\end{array}$} \\
\hline None & $64(70.3)$ & $31(73.8)$ & $16(64.0)$ & $3(60.0)$ & $14(73.7)$ \\
\hline Benzodiazepines & $27(29.7)$ & $11(26.2)$ & $9(36.0)$ & $2(40.0)$ & $5(26.3)$ \\
\hline \multicolumn{6}{|l|}{$\begin{array}{l}\text { HAD-A score (mean } \pm \text { standard } \\
\text { deviation) }\end{array}$} \\
\hline HAD-A score & $7.89 \pm 4.92$ & $3.81 \pm 2.24$ & $11.48 \pm 2.33 \neq$ & $4.00 \pm 1.58$ & $13.21 \pm 3.31 \neq$ \\
\hline \multicolumn{6}{|l|}{$\begin{array}{l}\text { HAD-D score (mean } \pm \text { standard } \\
\text { deviation) }\end{array}$} \\
\hline HAD-D score & $5.27 \pm 4.42$ & $2.55 \pm 1.99$ & $3.96 \pm 2.19 \S$ & $9.00 \pm 1.00 \neq$ & $12.05 \pm 3.17 \neq$ \\
\hline
\end{tabular}

The majority (67\%) of patients were admitted because of AMI. The median number of days until evaluation by the researchers was 4 (interquartile range: $2-7)$; the total number of days in hospital had a median of 9 (interquartile range: $7-16$ ). None of the patients died during the admission for which they were assessed.
Of the 91 patients in the sample, 44 patients ( $48.4 \%$ ) exhibited scores greater than or equal to 8 on the HAD-A subscale, characterizing a diagnostic estimate indicating anxiety. Analysis of the HAD-D subscale demonstrated that 24 patients $(26.4 \%)$ had scores that were clinically high enough to indicate depression (scores greater than or equal to 8 on the HAD-D subscale). Overall, 19 
patients $(20.9 \%)$ simultaneously had scores indicative of symptoms of anxiety and of depression and 42 patients $(46.1 \%)$ did not have scores indicating anxiety or depression (Table 2).

Table 2 - Presence of symptoms of anxiety and depression in patients admitted with acute coronary syndrome to a university hospital from May to October 2015, n (\%)

\begin{tabular}{lccc} 
& $\begin{array}{c}\text { No } \\
\text { depression } \\
\text { (HAD-D < 8) }\end{array}$ & $\begin{array}{c}\text { Depression } \\
\text { (HAD-D } \geq\end{array}$ & Total \\
\hline $\begin{array}{l}\text { No anxiety } \\
(\text { HAD-A < 8) }\end{array}$ & $42(46.1)$ & $5(5.5)$ & $47(51.6)$ \\
$\begin{array}{l}\text { Anxiety (HAD-A } \\
\geq 8)\end{array}$ & $25(27.5)$ & $19(20.9)$ & $44(48.4)$ \\
Total & $67(73.6)$ & $24(26.4)$ & $91(100)$ \\
\hline
\end{tabular}

The statistical analysis comparing patient data (sociodemographic) with HADS scores broken down into 4 groups (Table 1 ) did not detect significant relationships with any of the variables. However, when the patients with depressive symptoms ( $\mathrm{n}=$ 24) were analyzed irrespective of whether or not they had symptoms of anxiety, sex and marital status were significantly associated with depressive symptoms. Among the women, $37.5 \%$ had 8 points or more on the HAD-D, while $20.3 \%$ of the men had 8 or more points $(p<0.05)$. Data on marital status showed that $15.1 \%$ of married patients, $43.5 \%$ of those who were single or separated, and $40.0 \%$ of widowed patients scored 8 or more points ( $p=0.007)$.

Data on treatment of psychiatric disorders (Table 1 ) showed that 9 patients $(9.9 \%)$ were on treatments with psychotropic medications prescribed by a psychiatrist and $8(8.8 \%)$ prescribed by a clinician, 13 $(14.3 \%)$ had stopped a treatment more than 2 years previously and 61 (67\%) had never been treated with psychopharmaceuticals. None of the patients interviewed had a history of psychiatric admission. With regard to current psychotropic medication use, 5 patients $(5.5 \%)$ were taking benzodiazepines, $8(8.8 \%)$ were taking antidepressives, $4(4.4 \%)$ were taking antidepressives and benzodiazepines, and 74 (81.3\%) were not taking any such medication. During their time in hospital, 27 of the 82 patients who had never taken benzodiazepines previously were given prescriptions for a medication in this category.

\section{Discussion}

The sample of patients with ACS investigated had a high prevalence of scores clinically high enough to indicate anxiety and depression (48.4 and 26.4\% respectively). Similar findings have been reported in earlier studies, varying from 30 to $40 \%$ for symptoms of anxiety ${ }^{20-22}$ and from 15 to $30 \%$ for depressive symptoms. ${ }^{32}$ There is also evidence of psychiatric subdiagnosis among these patients, since just 17 patients from the whole sample (18.6\%) were being treated with psychotropics. Five of these 17 were only taking benzodiazepines.

Depression has significant harmful effects on the course and outcome of CAD. the probability of depressed patients having a more severe cardiac event within 12 months of a diagnosis of CAD is twice the probability for patients who are not depressed. ${ }^{33}$ The risk of cardiac mortality among patients with CAD is increased by two to four times for those who have depression. ${ }^{34}$

There was a high prevalence of comorbidity with both anxiety and depression, which has also been reported in other studies $8,9,35-38 ; 20.9 \%$ of our entire sample had HAD-A and HAD-D scores $\geq 8$. Among patients who scored high enough to indicate symptoms of anxiety, $43.2 \%$ also had scores indicative of depression; among those who had clinically elevated depression scores, $79.1 \%$ also had clinically elevated scores for symptoms of anxiety. Mean anxiety scores among these patients were very high, at 13.21 (SD = 3.31 ) for symptoms of anxiety and 12.05 (SD = 3.17) for depressive symptoms. Statistical data suggest that depression and anxiety frequently occur together. The lifelong probability of an anxiety disorder in a person with a history of a depressive episode is estimated at $47-58 \%$, while $56 \%$ of patients with anxiety disorder will develop depression. ${ }^{39}$ Patients with comorbid anxiety and depression exhibit more chronic forms of psychopathology, with significantly higher functional compromise and greater resistance to psychiatric and clinical treatments. ${ }^{35,40,41}$

In one study, ${ }^{42}$ people with simultaneous generalized anxiety disorder and depressive disorder exhibited higher risk of subsequent cardiac death, suggesting that anxiety and depression may also interact in a synergic manner to affect CAD. The PROMOTION study $^{37}$ also showed that patients who had comorbid symptoms of anxiety and depression had significantly higher mortality.

Statistically significant relationships were also observed between both sex and marital status and scores positive for symptoms of depression (HAD-D). The higher prevalence of elevated depression scores among women $(37.5 \%$ of the women vs. $20.3 \%$ of the men) found in our study has also been described in the literature. ${ }^{43-45}$ Single or separated patients also exhibited a higher prevalence $(43.5 \%)$ of depressive 
symptoms, with statistical significance ( $p=0.007)$, when compared to those who were married/living with a partner $(15.1 \%)$ or widowed $(40.0 \%)$. Several different studies have reported similar findings indicating that being single is associated with greater dissatisfaction with life. ${ }^{46-48}$

Just $18.7 \%$ of the 91 patients studied were receiving some type of treatment from a psychiatrist or clinician that involved psychopharmaceuticals, which shows that many patients who had scores for symptoms of anxiety, for symptoms of depression, or for both disorders, were not receiving treatment. Published data show that although anxiety and depression are often observed in patients with clinical diseases, including coronary diseases, they are very often neither diagnosed nor treated.

With regard to use of benzodiazepines and/or antidepressants, our sample was also not representative; just 5 were taking benzodiazepines, 8 were taking antidepressants, and 4 were taking both. It was not possible to establish any associations between these psychopharmaceuticals and prevalence of symptoms of anxiety or depression.

There were no statistically significant associations between patients who were medicated with benzodiazepines during their time in hospital and symptoms of anxiety and/or depression. Despite this, $33 \%$ of the patients who had not been using this class of medications were medicated with a benzodiazepine during their hospital stay, revealing a high rate of prescription of these drugs in the hospital setting.

\section{Limitations of the study}

Certain methodological limitations of this study merit consideration. The small sample studied compromises analysis of certain possible associations, such as, for example, use of psychopharmaceuticals and symptoms of anxiety or depression, since few of the patients in our sample were being treated with these medications. The sample was also compiled by convenience and patients were lost to the sample during data collection. There are no data on how many patients were admitted for ACS to the HSL during the study period. The patients interviewed were also asked about their symptoms during the previous week and some of them had already been in hospital for at least 7 days. These patients might have exhibited symptoms of anxiety and depression with onset during the current admission. The study also relied on a screening instrument for symptoms of anxiety and depression and diagnostic confirmation was not performed.

\section{Conclusions}

The results of this study are in line with published data and show that symptoms of anxiety and depression are prevalent among patients admitted for acute coronary syndrome. Patients who exhibited symptoms of anxiety and depression simultaneously had higher HADS scores for both disorders, suggesting that these patients need more intensive care.

Few of the patients in our sample were receiving treatment for anxiety or depression with psychopharmaceuticals, suggesting that these disorders continue to be under-diagnosed and under-treated.

\section{References}

1. Mendis S, Puska P, Norrving B. Global atlas on cardiovascular disease prevention and control. Geneva: World Health Organization; 2011.

2. Brotman DJ, Golden SH, Wittstein IS. The cardiovascular toll of stress. Lancet. 2007;370:1089-100.

3. Rosengren A, Hawken S, Ounpuu S, Sliwa K, Zubaid M, Almahmeed WA, et al. INTERHEART Investigators. Association of psychosocial risk factors with risk of acute myocardial infarction in 11119 cases and 13648 controls from 52 countries (the INTERHEART study): casecontrol study. Lancet. 2004;364:953-62.

4. Cohen $B E$, Edmondson D, Kronish IM. State of the art review: depression, stress anxiety, and cardiovascular disease. Am J Hypertens. 2015;28:1295-302.

5. Lichtman JH, Bigger JT Jr, Blumenthal JA, Frasure-Smith $\mathrm{N}$ Kaufmann PG, Lespérance $F$, et al. Depression and coronary heart disease: recommendations for screening, referral, and treatment: a science advisory from the American Heart Association Prevention Committee of the Council on Cardiovascular Nursing, Council on Clinical Cardiology, Council on Epidemiology and Prevention, and Interdisciplinary Council on Quality of Care and Outcomes Research: endorsed by the American Psychiatric Association. Circulation. 2008;118:1768-75.

6. Lichtman JH, Froelicher ES, Blumenthal JA, Carney RM, Doering LV, Frasure-Smith N, et al. Depression as a risk factor for poor prognosis among patients with acute coronary syndrome: systematic review and recommendations: a scientific statement from the American Heart Association. Circulation. 2014;129:1350-69.

7. Roest AM, Martens EJ, de Jonge P, Denollet J. Anxiety and risk of incident coronary heart disease: a meta-analysis. J Am Coll Cardiol. 2010;56:38-46.

8. Meyer T, Hussein S, Lange HW, Herrmann-Lingen C. Anxiety is associated with a reduction in both mortality and major adverse cardiovascular events five years after coronary stenting. Eur J Prev Cardiol. 2015;22:75-82.

9. Moryś JM, Bellwon J, Adamczyk K, Gruchała M. Depression and anxiety in patients with coronary artery disease measured by means of self-report measures and clinican-rated instrument. Kardiol Pol. 2016;74:53-60.

10. Lawton R, Seed PT, Kordowicz M, Schofield P, Tylee A, Ashworth M. Using a patient-generated mental-health measure "PSYCHLOPS" to explore problems in patients with coronary heart disease. $\mathrm{Br}$ ] Gen Pract. 2014;64:e354-63.

11. Lane D, Carroll D, Ring C, Beevers DG, Lip GY. The prevalence and persistence of depression and anxiety following myocardial infarction. $\mathrm{Br}$ J Health Psychol. 2002;7:11-21.

12. Ruo B, Rumsfeld JS, Hlatky MA, Liu H, Browner WS, Whooley MA Depressive symptoms and health-related quality of life: the Heart and Soul Study. JAMA. 2003;290:215-21.

13. Rutledge $T$, Reis VA, Linke SE, Greenberg BH, Mills PJ. Depression in heart failure a meta-analytic review of prevalence, intervention effects, and associations with clinical outcomes. J Am Coll Cardiol. 2006;48:1527-37.

14. Ceccarini M, Manzoni GM, Castelnuevo G. Assessing depression in cardiac patients: what measures should be considered? Depress Res Treat. $2014 ; 2014: 148256$. 
15. Huffman JC, Smith FA, Blais MA, Beiser ME, Januzzi JL, Fricchione GL. Recognition and treatment of depression and anxiety in patients with acute myocardial infarction. Am J Cardiol. 2006;98:319-24.

16. Roest AM, Zuidersma $M$, de Jonge P. Myocardial infarction and generalised anxiety disorder: 10-year follow-up. $\mathrm{Br}$ J Psychiatry. 2012:200:324-9.

17. Frasure-Smith $\mathrm{N}$, Lespérance $\mathrm{F}$. Depression and anxiety as predictors of 2- year cardiac events in patients with stable coronary artery disease. Arch Gen Psychiatry. 2008;65:62-71.

18. Parker GB, Owen CA, Brotchie HL, Hyett MP. The impact of differing anxiety disorders on outcome following an acute coronary syndrome: time to start worrying? Depress Anxiety. 2010;27:302-9.

19. Tully PJ, Penninx BW. Depression and anxiety among coronary heart disease patients: can affect dimensions and theory inform diagnostic disorder-based screening? J Clin Psychol. 2012;68:448-61.

20. Carinci $F$, Nicolucci A, Ciampi A, Labbrozzi D, Bettinardi $O$, Zotti AM, et al. Role of interactions between psychological and clinical factors in determining 6-month mortality among patients with acute myocardial infarction. Application of recursive partitioning techniques to the GISSI-2 database. Gruppo Italiano per lo Studio della Sopravvivenza nell' Infarto Miocardico. Eur Heart J. 1997;18:835-45.

21. Frasure-Smith $N$, Lespérance $F$, Juneau $M$, Talajic $M$, Bourassa MG. Gender, depression and one-year prognosis after myocardial infarction. Psychosom Med. 1999;61:26-37.

22. Benninghoven $D$, Kaduk $A$, Wiegand $U$, Specht T, Kunzendorf S, Jantschek G. Influence of anxiety on the course of heart disease after acute myocardial infarction - risk factor or protective function? Psychother Psychosom. 2006;75:56-61.

23. Glassman AH, Shapiro PA. Depression and the course of coronary artery disease. Am J Psychiatry. 1998;155:4-11.

24. Rugulies R. Depression as a predictor for coronary heart disease: a review and meta-analysis. Am J Prev Med. 2002;23:51-61.

25. Zigmond AS, Snaith RP. The hospital anxiety and depression scale. Acta Psychiatr Scand. 1983;67:361-70.

26. Kaur S, Zainal NZ, Low WY, Ramasamy R, Sidhu JS. Factor Structure of Hospital Anxiety and Depression Scale in Malaysian patients with coronary artery disease. Asia Pac J Public Health. 2015;27:450-60.

27. Hunt-Shanks T, Blanchard C, Reid R, Fortier M, Cappelli M. A psychometric evaluation of the Hospital Anxiety and Depression Scale in cardiac patients: addressing factor structure and gender invariance. Br J Health Psychol. 2010;15:97-114.

28. Bambauer KZ, Locke SE, Aupont O, Mullan MG, McLaughlin TJ. Using the Hospital Anxiety and Depression Scale to screen for depression in cardiac patients. Gen Hosp Psychiatry. 2005;27:275-84.

29. Doyle F, Conroy R, McGee H, Delaney M. Depressive symptoms in persons with acute coronary syndrome: specific symptom scales and prognosis. J Psychosom Res. 2010;68:121-30.

30. Martin CR, Lewin RJP, Thompson DR. A confirmatory factor analysis of the Hospital Anxiety and Depression Scale in coronary care patients following acute myocardial infarction. Psychiatry Res. 2003;120:8594.

31. Botega NJ, Bio MR, Zomignani MA, Garcia C Jr, Pereira WA. [Mood disorders among inpatients in ambulatory and validation of the anxiety and depression scale HAD]. Rev Saude Publica. 1995;29:35563.

32. Frasure-Smith $N$, Lespérance $F$, Gravel G, Masson A, Juneau M, Talajic $M$, et al. Social support, depression, and mortality during the first year after myocardial infarction. Circulation. 2000;101:1919-24.

33. Burg MM, Meadows J, Shimbo D, Davidson KW, Schwartz JE, Soufer R. Confluence of depression and acute psychological stress among patients with stable coronary heart disease: effects on myocardial perfusion. J Am Heart Assoc. 2014;30:3:e000898.
34. Pinton FA, Carvalho CF, Miayazaki MCOS, Godoy MF. Depressão como fator de risco de morbidade imediata e tardia pós-revascularização cirúrgica do miocárdio. Rev Bras Cir Cardiovasc. 2006;21:68-74.

35. Watkins LL, Koch GG, Sherwood A, Blumenthal JA, Davidson JR, $\mathrm{O}$ 'Connor $\mathrm{C}$, et al. Association of anxiety and depression with allcause mortality in individuals with coronary heart disease. J Am Heart Assoc. 2013;2:000068.

36. Pajak A, Jankowski P, Kotseva K, Heidrich J, de Smedt D, De Bacquer D, et al. EUROASPIRE Study Group. Depression, anxiety, and risk factor control in patients after hospitalization for coronary heart disease: the EUROASPIRE III Study. Eur J Prev Cardiol. 2013;20:33140.

37. Doering LV, Moser DK, Riegel B, McKinley S, Davidson $\mathrm{P}$, Baker $\mathrm{H}$, et al. Persistent comorbid symptoms of depression and anxiety predict mortality in heart disease. Int J Cardiol. 2010;145:188-92.

38. Walters $P$, Barley EA, Mann A, Phillips $R$, Tylee A. Depression in primary care patients with heart disease: baseline findings from the UPBEAT UK study. PLoS One. 2014;9:e98342.

39. Beekman AT, de Beurs E, Van Balkom AJ, Deeg DJ, van Dyck R, van Tilburg W. Anxiety and depression in later life: co occurrence and communality of risk factors. Am J Psychiatry. 2000;157:89-95.

40. Zajecka JM, Ross JS. Management of comorbid anxiety and depression. J Clin Psychiatry. 1995;56:10-3.

41. Ghaemi SN. Why antidepressants are not antidepressants: STEP$B D, S T A R * D$, and the return of neurotic depression. Bipolar Disord. 2008; 10:957-68.

42. Phillips AC, Batty GD, Gale CR, Deary IJ, Osborn D, MacIntyre K, et al. Generalized anxiety disorder, major depressive disorder, and their comorbidity as predictors of all-cause and cardiovascular mortality: the Vietnam experience study. Psychosom Med. 2009;71:395-403.

43. Mattos MA, Lougon M, Tura BR, Pereira BB. Depressão e síndrome isquêmica coronariana aguda. Rev SOCERJ. 2005;18:288-94.

44. Gerber $Y$, Weston SA, Killian JM, Jacobsen SJ, Roger VL. Sex and classic risk factors after myocardial infarction: a community study. Am Heart J. 2006; 152:461-8.

45. Leifheit-Limson EC, D'Onofrio G, Daneshvar M, Geda M, Bueno $H_{\text {, }}$ Spertus JA, et al. Sex differences in cardiac risk factors, perceived risk, and health care provider discussion of risk and risk modification among young patients with acute myocardial infarction: the VIRGO study. J Am Coll Cardiol. 2015;66:1949-57.

46. Gulliksson M, Burell G, Lundin L, Toss H, Svärdsudd K. Psychosocial factors during the first year after a coronary heart disease event in cases and referents. Secondary Prevention in Uppsala Primary Health Care Project (SUPRIM). BMC Cardiovasc Disord. 2007; 7:36

47. Rohyans LM, Pressler SJ. Depressive symptoms and heart failure: examining the sociodemographic variable. Clin Nurse Spec. 2009;23:138-44.

48. Luttik ML, Jaarsma T, Veeger N, van Veldhuisen DJ. Marital status, quality of life, and clinical outcome in patients with heart failure. Heart Lung 2006;35:3-8.

\section{Correspondence:}

Carolina Casanova Meneghetti

Rua Ramiro Barcelos, 1056/402

90035-006 - Porto Alegre, RS - Brazil

E-mail: meneghetti.cc@gmail.com 